\title{
PENGARUH SISTEM INFORMASI AKUNTANSI, GAYA KEPEMIMPINAN, DAN MOTIVASI KERJA TERHADAP KINERJA KARYAWAN PADA KANTOR POS JEMUR ANDAYANI SURABAYA
}

\author{
*Suci Gustia Nanda, Mahsina, Tri Lestari \\ Fakultas Ekonomi dan Bisnis Universitas Bhayangkara Surabaya, Indonesia
}

DOI: $10.46821 /$ ekobis.v1i1.9

\begin{abstract}
ABSTRAK
Tujuan penelitian dari penelitian ini adalah untuk mengetahui pengaruh sistem informasi akuntansi, gaya kepemimpinan, dan motivasi kerja terhadap kinerja karyawan. Populasi pada penelitian ini adalah karyawan yang bekerja di perusahaan yang bergerak dibidang pelayanan jasa pada kantor pos jemur andayani Surabaya dan jumlah responden pada penelitian ini adalah 25 responden. Metode yang digunakan adalah metode kuantitatif metode analisis data menggunakan analisis regresi linier berganda dan proses menggunakan applikasi SPSS. Hasil penelitian menunjukkan bahwa secara parsial membuktikan bahwa gaya kepemimpinan berpengaruh positif terhadap kinerja karyawan. Sedangkan sistem informasi akuntansi dan motivasi kerja tidak berpengaruh positif terhadap kinerja karyawan.
\end{abstract}

Kata Kunci: Sistem Informasi Akuntansi, Gaya Kepemimpinan, Motivasi Kerja, Kinerja Karyawan

\begin{abstract}
The research objective of this study was to determine the effect of accounting information systems, leadership styles, and work motivation on employee performance. The population in this study are employees who work in a company engaged in services at the post office in Surabaya and serve Surabaya. The number of respondents in this study were 25 respondents. The method used is a quantitative method of data analysis using multiple linear regression analysis and the process using the SPSS application. The results showed that partially proving that leadership style had a positive effect on employee performance. While accounting information systems and work motivation do not have a positive effect on employee performance.
\end{abstract}

Keywords: Accounting Information Systems, Leadership Style, Work Motivation, Employee Performance 


\section{PENDAHULUAN}

Era globalisasi mengakibatkan perkembangan teknologi semakin pesat. Hal ini tentu saja juga berakibat semakin ketatnya persaingan dunia bisnis. Sejalan dengan perkembangan teknologi, perkembangan indstri jasa saat ini juga semakin meningkat.

Dengan adanya perubahan lingkungan perusahaan yang semakin kompleks dan kompetitif, setiap perusahaan dituntut untuk siap menghadapi perkembangan teknologi, mengatasi segala kebutuhan konsumen, dan mengahadapi persaingan yang ketat dengan perusahaan lain. Perusahaan yang ingin tetap bertahan harus meghadapi perubahaan tersebut dengan strategi masing-masing.

Salah satu srategi tersebut adalah dengan meningkatkan kinerja karyawannya. Suatu perusahaan dapat dikatakan berhasil dengan melihat berbagai faktor salah satunya yaitu melihat baik buruk kinerja dari karyawan.

Kantor pos sebagai badan usaha milik Negara (BUMN) yang mengembangkan misi layanan jasa pos yang saat ini mengahadapi tantangan yang berat. Berbagai perangkat komunikasi yang semakin canggih membuat masyarakat mualai meninggalkan layanan pengiriman surat dan perkembangan teknologi yang terjadi setiap adanya mesin fax, telepon, handphone, dan internet membuat penyampaian pesan begitu mudah dan praktis, sehingga mempengaruhi kegiatan usaha pos Indonesia.

Oleh karena itu, dalam upaya mencapai tujuan perushaan seorang atasan memberikan suatu gaya kepemimpinan yang membuat karyawan bias mengerjakan tugasnya dengan baik. Dengan pertimbangan ini peneliti ingin memfokuskan penelitian pada kinerja setiap individu karyawan, seberapa besar pengaruh sistem informasi akuntansi pada gaya kepemimpinan terhadap kienerja karyawan. Hal tersebut bertujuan untuk mengetahui bagaimana proses kegiatan karyawan.

\section{TINJAUAN PUSTAKA}

\section{Sistem Informasi Akuntansi}

Menurut Mulyadi (2008) Mulyadi mengatakan bahwa sistem informasi akuntansi merupakan suatu bentuk sistem informasi yang memiliki tujuan untuk menyediakan informasi bagi pengelola kegiatan usaha, memperbaiki informasi yang dihasilkan oleh sistem yang sudah ada sebelumnya, memperbaiki pengendalian akuntansi dan juga pengecekan internal, serta membantu memperbaiki biaya klerikal dalam pemeliharaan catatan akuntansi.

\section{Gaya Kepemimpinan}

Menurut Maisah (2010) pemimpin adalah suatu proses yang mempengaruhi oleh seseorang dalam mengelola anggota kelompoknya untuk mencapai tujuan organisasi. Kepemimpinan merupakan bentuk strategi atau teori memimpin yang tentunya dilakukan oleh orang yang biasa kita sebut sebagi pemimpin. Pemimpin adalah seseorang dengan wewenang kepemimpinannya mengarahkan bawahannya untuk mengerjakan sebagian dari pekerjaannya dalam mencapai tujuan.

Dari penjelasan mengenai gaya kepemimpinan diatas, jelas bahwa betapa pentingnya peranan gaya kepemimpinan dalam perusahaan untuk mencapai tujuan perusahaan yang lebih baik. 


\section{Motivasi Kerja}

Menurut Mangkunegara (2011), mengemukakan bahwa motivasi kerja didefiniskan sebagai kondisi yang berpengaruh membangkitkan, mengarahkan dan memelihara perilaku yabng berhuungan dengan lingkungan kerja.

\section{Kinerja Karyawan}

Menurut Sedarmayanti (2009:176) mengemukkan bahwa "kinerja sebagai hasil kerja yang daoat dicapai oleh seseorang atau sekelompok orang dalam suatu oraganisasi, sesesuai dengan wewenang dan tanggungjawab masing-masing dalam mencapai tujuan organisasi bersangkutan secara legal, tidak melanggar hokum dan sesuai dengan moral maupun etika."

\section{METODE PENELITIAN}

\section{Definisi Variabel Independen dan Variabel Dependen}

\section{Variabel Independen}

a. Sistem Informasi Akuntansi (X1).

Menurut Widjayanto (2001:7) mengemukakan bahwa sistem informasi akuntansi adalah susunan berbagai formulir, catatan, peralatan teramasuk computer dan perlengkapnya, serta alat komunikasi, tenaga pelaksanaanya, dan laporan yang dikoordinasikan secara erat yang didesain untuk mentrasformasikan data keuangan menjadi informasi yang dibutuhkan manajemen.

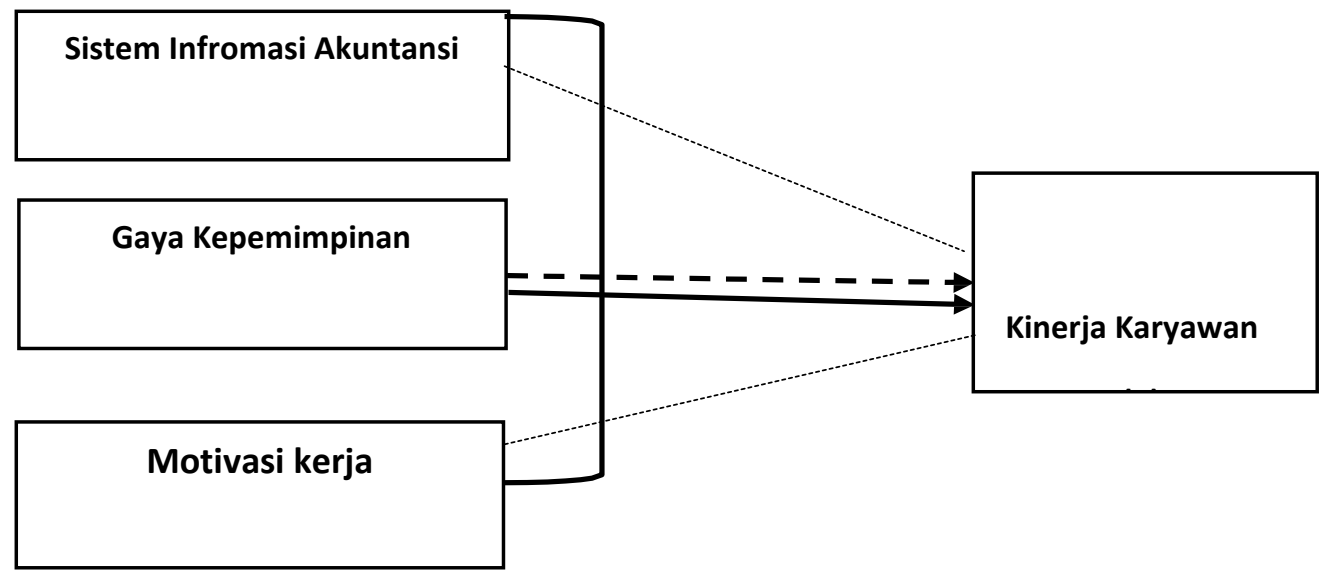

\section{Keterangan :}

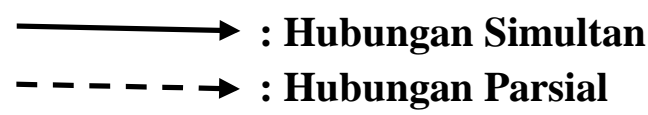

Sumber: Peneliti, 2019

Gambar 1

Kerangka Konsetual 
b. Gaya Kepemimpinan (X2)

Menurut Hasibuan (2017:171) menjelaskan gaya kepemimpinan adalah cara seseorang pemimpin mempengaruhi perilaku bawahannya yang bertujuan untuk mendorong gairah kerja, kepuasan dan produktivitas karyawan yang tinggi, agar dapat mencapai tujuan organisasi yang maksimal.

c. Motivasi Kerja (X3)

Menurut Robbins (2006:166) mengemukakan bahwa motivasi kerja didefiniikan sebagai kesediaan untuk mengeluarkan tingkat upaya yang tinggi untuk tujuan organisasi, yang dikondisikan oleh kemapuan upaya itu untuk memenuhi kebutuhan individual.

\section{Variabel Dependen}

a. Kinerja Karyawan $(\mathrm{Y})$

Menurut Srimulyo (1999:33) menyatakan bahwa inerja atau presntasi kinerja adalah hasil krja seseoramg atau kelompok selama periode tertentu dibandingkan dengan bergabagai kemungkinan, missal standart, target atau sasaran kriteria yang telah ditentukan terlebih dahulu dan disepakati bersama.

\section{Populasi dan Sampel}

Populasi pada penelitian ini berjumlah 58, tetapi sampel yang digunakan dalam penelitian ini hanya berjumlah 25 responden. Dalam penelitian ini yang menjadi sampel adalah seluruh karyawan Kantor Pos Jemur Andayani Surabaya.

\section{Lokasi dan Waktu Penelitian}

Penelitian ini telah dilaksanakan di Kantor Pos Jemur Andayani yang berlokasi di Jl. Jemur Andayani No. 75, Kendangsari, Tenggilis Mejoyo, Kota SBY, Jawa Timur 60292, dan waktu penelitian ini dilakasanakan pada bulan Juli 2019 sampai dengan data yang diperlukan lengkap.

\section{Sumber Data}

Sumber data yang digunakan adalah data primer yang diperoleh dari hasil penyebaran kuesioner yang telah diisi oleh responden.

\section{HASIL ANALISIS DAN PEMBAHASAN Hasil Analisis Data}

Tabel 1

Hasil Uji Analisis Linier Berganda Coefficien

\begin{tabular}{|c|c|c|c|c|c|}
\hline \multirow[b]{2}{*}{ Model } & \multicolumn{2}{|c|}{ Unstandardized Coefficients } & \multirow{2}{*}{$\begin{array}{c}\text { Standardized } \\
\text { Coefficients }\end{array}$} & \multirow[t]{2}{*}{$\mathrm{T}$} & \multirow[t]{2}{*}{ Sig. } \\
\hline & $\mathrm{B}$ & Std. Error & & & \\
\hline 1 (Constant) & 16.451 & 9.913 & & 1.660 & .112 \\
\hline SIA (X1) & .111 & .410 & .063 & .271 & .789 \\
\hline $\mathrm{X} 2$ & .257 & .238 & .249 & 3.079 & .000 \\
\hline $\mathrm{X} 3$ & -.058 & .397 & -.033 & -.147 & .885 \\
\hline
\end{tabular}

Sumber: Data Primer Diolah, 2019 
Berdasarkan tabel 1, coeffients menentukan garis persamaan regresi, Rumus persamaan garis regresi berganda secara umum, sebagai berikut :

$\mathrm{Y}=16.451+0.111(\mathrm{X} 1)+0.257(\mathrm{X} 2)+0.058(\mathrm{X} 3)+\mathrm{e}$

\section{Hasil Uji t}

1. Sistem Informasi Akuntansi (X1), Dari hasil analisis dketahui bahwa nilai $t_{\text {hitung }}$ sebesar 0.721 dan nilai $t_{\text {tabel }} 2.074$ yang artinya $t_{\text {hitung }}$ lebih kecil dari $t_{\text {tabel }}$ $(0.721<2.074)$ serta nilai signifikan $0.789>0.05$ maka Ho diterima Ha ditolak, berarti variabel Sistem informasi akuntansi ini tidak berpengaruh signifikan terhadap Kinerja Karyawan.

2. Gaya Kepemimpinan (X2), Dari hasil analisis dketahui bahwa nilai $t_{\text {hitung }}$ sebesar 3.079 dan nilai $t_{\text {tabel }} 2.074$ yang artinya $t_{\text {hitung }}$ lebih besar dari $t_{\text {tabel }}$ (3.079>2.074) serta nilai signifikan $0.000<0.05$ maka Ho ditolak Ha diterima, berarti variabel Gaya Kepemimpinan berpengaruh signifikan terhadap kinerja karyawan.

3. Motivasi Kerja (X3), Dari hasil analisis dketahui bahwa nilai $t_{\text {hitung }}$ sebesar 0.147 dan nilai $t_{\text {tabel }} 2.074$ yang artinya $t_{\text {hitung }}$ lebih kecil dari $t_{\text {tabel }}(-$ $0.147<2.074$ ) serta nilai signifikan $0.885>0.05$ maka Ho diterima Ha ditolak, berarti variabel Motivasi Kerja tidak berpengaruh signifikan terhadap kinerja karyawan.

\section{Hasil Uji F}

Pada uji $\mathrm{F}$ bertujuan untuk mengetahui apakah semua variabel independen dapat dipakai dalam model regresi ini yang memiliki pengaruh signifikan secara bersama- sama terhadap dependen. Hasil dapat dilihat pada tabel.

Berdasarkan tabel diatas menginformasikan bahwa variabel X1, X2, X3 dan $\mathrm{Y}$ adalah signifikan. Hal itu terlihat dari nilai $\mathrm{F}$ sebesar 0.551 dengan melihat nilai signifikan ( $p$ value <0.05), sehingga didapati niali signifikan $F$ sebesar $0.653<0.05$. hal itu menjealskan bahawa hubunga antar variabel adalah signifikan.

Untuk menentukan variabel dominan dapat dilihat dari rangking koefisien regresi pada Sandarrized coefisients beta dari masing-masing variabel bebas. Jika salah satu variabel bebas memiliki nilai standardized coefisients beta tertinggi diantara variabel lainnya, maka variabel tersebut dapat dikatkan berpengaruh dominan.

Berdasarkan Tabel 2, hasil penentian variael dominan diketahui nilai standardized coefisients beta untuk variabel Sistem Informasi Akuntansi (X1) = 0.063, Gaya kepemimpinan $(X 2)=0.249$, Motivasi Kerja $(X 3)=0.033$.

Tabel 2

\section{Hasil Uji F}

ANOVA

\begin{tabular}{|c|c|c|c|c|c|c|}
\hline & Sum of Squares & \multirow{2}{*}{$\frac{\mathrm{Df}}{3}$} & \multirow{2}{*}{$\frac{\text { Mean Square }}{4.618}$} & \multirow{2}{*}{$\frac{F}{.551}$} & \multirow{2}{*}{$\frac{\text { Sig. }}{.653^{b}}$} \\
\hline \multicolumn{2}{|c|}{$\begin{array}{ll}\text { Model } \\
1 & \text { Regression }\end{array}$} & \multirow{3}{*}{$\begin{array}{l}13.855 \\
175.985 \\
189.840\end{array}$} & & & & \\
\hline & & \multirow{2}{*}{$\begin{array}{l}21 \\
24\end{array}$} & \multirow[t]{2}{*}{8.380} & & \\
\hline & $\begin{array}{l}\text { Regression } \\
\text { Residual } \\
\text { Total }\end{array}$ & & & & & \\
\hline
\end{tabular}

a. Dependent Variable: Kinerja Karyawan

b. Predictors: (Constant), X1, X2, X3

Sumber: Data Primer Diolah, 2019 


\section{Tabel 3}

Hasil Penentuan Variabel Dominan Coefficients $^{\mathbf{a}}$

\begin{tabular}{llccc}
\hline & & \multicolumn{2}{c}{$\begin{array}{c}\text { Unstandardized } \\
\text { Coefficients }\end{array}$} & $\begin{array}{c}\text { Standardized } \\
\text { Coefficients }\end{array}$ \\
\cline { 2 - 4 } Model & B & Std. Error & Beta \\
\hline 1 & (Constant) & 16.45 & 9.913 & \\
& SIA (X1) & .111 & .410 & .063 \\
& Gaya Kepemimpinan X2 & .257 & .238 & .249 \\
\multicolumn{2}{l}{ Motivasi Kerja X3 } & -.058 & .397 & -.033 \\
\hline
\end{tabular}

Sumber: Data Primer Diolah, 2019

\section{SIMPULAN}

Hipotesis Pertama (Pengaruh Sistem Informasi Akuntansi Terhadap Kinerja Karyawan) Dari hasil analisis dketahui bahwa nilai thitung sebesar 0.721 dan nilai ttabel 2.074 yang artinya thitung lebih kecil dari ttabel $(0.721<2.074)$ serta nilai signifikan 0.789>0.05 maka Ho diterima Ha ditolak, berarti variabel Sistem informasi akuntansi ini tidak berpengaruh signifikan terhadap Kinerja Karyawan. Hasil ini menunjukkan bahwa sistem informasi akuntansi berpenagruh negatif dan tidak signifikan terhadap kinerja karyawan. Hasil tersebut sama dengan penelitian yang dilakkan oleh Listina (2017). Penelitian yang dilakukan di kantor pos jemur andayani menunujukkan adanya respon positif terhadap penggunaan sistem informasi akuntansi pada perusahaan tersebut, para responden memberikan persepsi yang cukup baik. Hipotesis Kedua (Pengaruh Gaya Kepemimpinan Terhadap Kinerja Karyawan pada kantor pos jemur andayani surabaya) Dari hasil analisis dketahui bahwa nilai thitung sebesar 3.079 dan nilai ttabel 2.074 yang artinya thitung lebih besar dari ttabel (3.079>2.074) serta nilai signifikan $0.000<0.05$ maka Ho ditolak Ha diterima, berarti variabel Gaya Kepemimpinan berpengaruh signifikan terhadap kinerja karyawan. Dari penjelasan tersebut dapat disimpulkan bahwa Ho ditolak berarti ada pengaruh gaya kepemimpinan (X2) terhadap Kinerja Karyawan pada kantor pos jemur andayani Surabaya. Hasil tersebut sama dengan apa yang dilakukan oleh Putri (2016). Hipotesis Ketiga (Pengaruh Motivasi Kerja Terhadap Kinerja Kayawan), Dari hasil analisis dketahui bahwa nilai thitung sebesar -0.147 dan nilai ttabel 2.074 yang artinya thitung lebih kecil dari ttabel $(-0.147<2.074)$ serta nilai signifikan $0.885>0.05$ maka Ho diterima Ha ditolak, berarti variabel Motivasi Kerja tidak berpengaruh signifikan terhadap kinerja karyawan. maka variabel ini tidak memiliki nilai signifikan. Dari penjelasan tersebut dapat disimpulkan bahwa Ho diterima berarti tidak ada pengaruh Motivasi Kerja (X3) terhadap Kinerja Karyawan (Y) pada kantor pos jemur andayani Surabaya. Hasil Tersebut tidak sesuai dengan penelitian yang dilakukan oleh Khairunnisa (2017). Untuk peneliti selanjutnya diharapkan melihat ke perusahaan untuk meningkatkan Sistem infromasi akuntansi pada kantor pos untuk meningkatkan kimerja karyawan agar lebih baik 
lagi untuk mengerjakan sesuatu yang bersnagktan dengan sitem informasi akuntansi. Untuk peneliti selanjutnya, disarankan survey dengan metode lain untuk menilai gaya kepemimpinan agar dapat terus mempertahankan pemimpin yang baik agar kinerja karyawan dapat lebih baik lagi. Diharapkan pimpinan diperushaan dapat memotivasi karyawan atau bawahan lebih baik lagi agar kinerja karyawan atau bawahan bisa lebih baik lagi mengerjakan tugas yang dikerjakan.

\section{DAFTAR PUSTAKA}

Eny, 2015. Pengaruh sistem informasi akuntansi, Gaya kepemimpinan, dan kompleksitas kerja lampung. Skripsi universitas lampung.

Mangkunegara, 2011. Manajemen Sumber Daya Manusia Perusahaan, Rosdakarua, Bandung.

Putra, indra. 2015. Pengaruh tingkat pendidikan dan disiplin kerja terhadap kinerja karyawan pada hotel amaravathy resort. Skripsi.

Putu, Gede Adi, Ananta, 2017. Pengaruh sistem informasi akuntansi dan budaya organisasi

Rizaldi, Fahmi, 2015. Pengaruh Sistem Informasi Akuntansi Terhadap Kinerja Karyawan CV Teguh Karya Utama Surabaya. Jurnal Ilmu \& Riset Akuntansi, Volume 4 Nomor 10

Robbins, S.P. (2006). Perilaku Organisasi, PT. Jakarta: PT. Gramedia

Sedarmayanti, 2009. Sumber Daya Manusia dan Produktivitas Kerja, Mandar Maju, Bandung

Sugiyono, 2016. Metode Penelitian Kuantitatif dan Kualitatif. Hal 81-82

Sukaryati, dhani. 2016. Pengaruh budaya organisasi, dan motivsasi kerja pada badan pusat statistic terhadap kinerja karyawan. Skripsi. Universitas Islam Batik. Surakata

terhadap kinerja organisasi hotel di kabupaten buleleng. E-jurnal S1, akuntansi program S1(Vol : 7 No. 1 Tahun 2017)

Thoha, Miftah. 2007. Kepemimpinan dalam manajemen. Jakarta: PT. Raja Grafindo Persada 